\title{
DEVELOPMENT OF TECHNOLOGIES FOR A CMC-BASED COMBUSTION CHAMBER
}

\author{
O. J. Haidn, J. Riccius, D. Suslov, S. Beyer, and O. Knab
}

Within the 'Propulsion 2010' Memorandum of Understanding (MoU) which was signed in 2006, Astrium and DLR agreed to work jointly on Ceramic Matrix Composite (CMC) materials and related technologies with the aim to have finally within the next three years all components and subsystems available for an entirely CMC-based thrust chamber assembly. Hence, propellant injection, combustion chamber liner, and appropriate cooling technologies as well as CMC nozzle parts will be developed and tested within the years to come. The paper reports the current status and focuses on propellant injection applying a porous face plate, heat and mass transfer within and along an effusion-cooled porous combustion chamber liner and design and heat transfer issues of a cooled thrust nozzle.

\section{INTRODUCTION}

Various technology programmes in Europe are concerned with preparing for future propulsion technologies to reduce the costs and increase the lifetime of liquid rocket engine (LRE) components. The application of modern and innovative materials and fabrication processes has become a major factor within the process of designing new components and developing new technologies in order to fulfil the future requirements and for realizing reusable and robust engine components. One of the key technologies of concern for various engine manufacturers worldwide is the development of fibre-reinforced ceramics - CMCs. The advantages for the developers are obvious - low specific weight, high specific strength over a large temperature range, and good damage tolerance compared to monolithic ceramics make this class of materials extremely interesting. Both partners of the 'Propulsion 2010' project have been active within the last years on various levels to develop materials and component design methods, system analyses, propellant injection and heat transfer issues, and mechanical load handling aspects [1-10].

Within the 'Propulsion 2010' project, a work split has been agreed upon where Astrium concentrates its efforts on the development of a regenerative cooled nozzle applying their SICTEX ${ }^{\circledR}(\mathrm{C} / \mathrm{SiC})$ material and a radiation-cooled 
nozzle extension which could be fabricated either from the standard material SICARBON ${ }^{\circledR}$ (C/SiC made by Liquid Polymer Infiltration) or the newly developed CARBOTEX ${ }^{\circledR}(\mathrm{C} / \mathrm{C})$ [2, 8-12]. The work packages of DLR Institute of Space Propulsion include the effusion-cooled C/C liner and throat technology which has been developed over the last ten years in cooperation with the DLR Institute of Structures and Design, a propellant injection system which relies on a porous face plate and simple oxidizer holes, qualification test of all components and subsystems as well as the final ceramic thrust chamber assembly test at the high pressure facility $\mathrm{P} 8[1,3-7,9,13-15]$. Within the project, the most critical issues, adjustment of material properties to the local cooling needs, proof of reproducibility and robustness of design methodology and production processes and leakages and, most important, development and validation of scaling laws will be dealt with.

\section{THRUST CHAMBER TECHNOLOGIES}

\subsection{System Analyses}

In the beginning, intense system analysis studies have been performed at DLR to identify potential applications of CMCs in thrust chambers and their specific requirements as well as to qualify, as soon as possible, critical issues of typical operational loads of LREs. While the pressure losses in the cooling channels of typical regenerative cooled LREs may reach up to $50 \%$ of the combustion chamber pressure, the driving pressure for an effusion cooled liner may be as low as

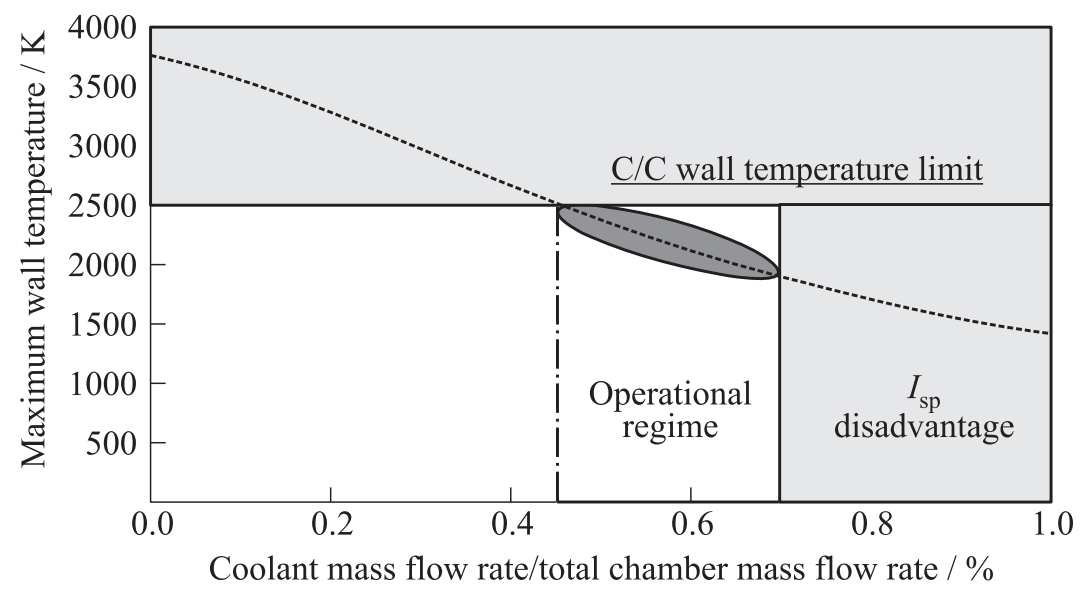

Figure 1 Operational domain of an effusion-cooled thrust chamber liner 
the pressure drop across the propellant injection system. This advantage may be traded in the system among other options to either lower the requirements for the turbopump or increase the combustion chamber pressure. For comparison reasons, the Vulcain 2, a gas generator cycle, was analyzed without taking into account the hydrogen mass flow rate applied for film cooling. The wall temperature of an effusion-cooled chamber liner as a function of blowing ratio is shown in Fig. 1. In particular, the domain where such a thrust chamber can be operated without any penalty on the specific impulse of the overall system caused by the effusion cooling is shown in Fig. 1. Clearly, it requires materials which tolerate temperatures above $2200 \mathrm{~K}$ at blowing ratios which should not exceed $0.6 \%$. In a real application, the $I_{\text {sp }}$ penalty would be even lower and therefore higher coolant mass flow rates will be possible since the skin friction along the liner walls will become almost negligible and thus, the pressure losses inside the chamber would be considerably smaller in a chamber with effusion cooling.

\subsection{Heat and Mass Transfer in Porous Walls}

In order to fully realize the potentials of CMC materials, the final development is an integral thrust-chamber assembly with a CMC liner with an outer load bearing carbon-fiber reinforced polymer (CFRP) and a CMC injection head. The main challenge of effusion cooling is the continuous adaptation of the local coolant supply to the varying heat fluxes. At each surface element of the liner, static and dynamic pressure of both coolant and hot gas have to be balanced to prevent entrainment of hot gases into the porous $\mathrm{C} / \mathrm{C}$ structure. The axial distribution of key parameters such as temperature, static and dynamic pressure, and heat flux along the thrust chamber liner which have a significant influence on the performance of the effusion cooling design are demonstrated in Fig. 2. The drastic changes in pressure and heat flux require a design of the porous material and the effusion-cooling flow rate such that the injected coolant mass flow rate locally outbalances both, the heat flux and the total pressure. In order to develop numerical tools for a design and layout of the cooling system, DLR has performed detailed studies of the coupled heat and mass transfer in such a thrust chamber taking into account nonhomogeneous heat and mass transport properties of the ceramic material. These CFD analyses were performed with a standard compressible $k-\varepsilon-$ RANS (Reynolds averaged Navier-Stokes) code assuming two-dimensional (2D) rotational symmetry. The coupled analysis of hot gases and coolant ("multispecies") was performed assuming ideal gas. The flow within the pores was modeled with a distributed resistance approach according to Forchheimer. The transport equation for the $i$ th species reads

$$
\frac{1}{r} \frac{\partial\left(r \rho \Phi_{i} v_{r}\right)}{\partial r}+\frac{\partial\left(\rho \Phi_{i} v_{x}\right)}{\partial x}-\frac{\partial}{\partial r}\left(\rho D_{m i} \frac{\partial \Phi_{i}}{\partial r}\right)-\frac{\partial}{\partial x}\left(\rho D_{m i} \frac{\partial \Phi_{i}}{\partial x}\right)=0
$$




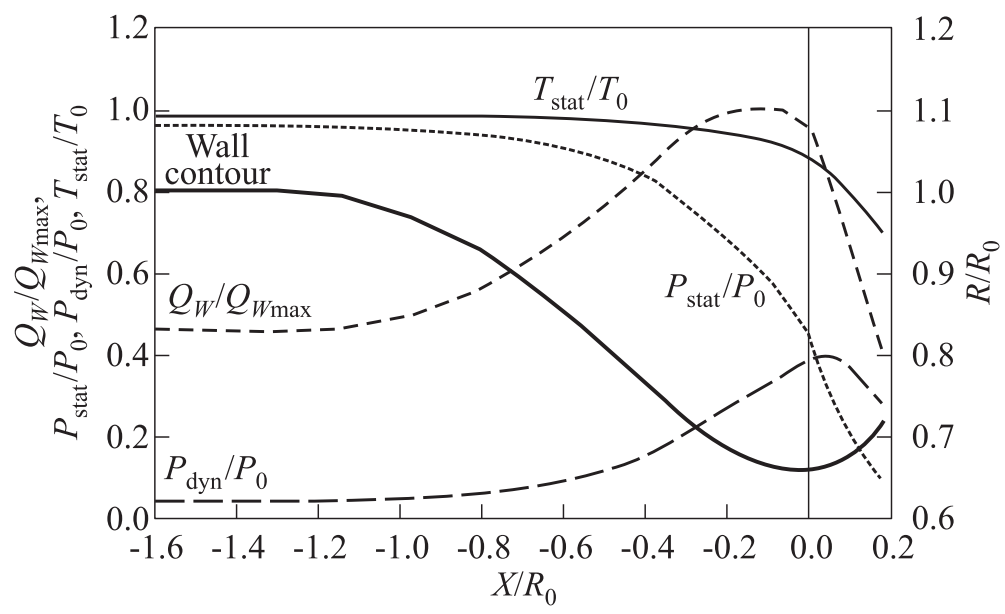

Figure 2 Axial distribution of typical thrust chamber parameters

where $\Phi_{i}$ is the mass fraction of the $i$ th species; $n$ is the number of species considered; and $D_{m i}$ is the diffusion coefficient of the $i$ th species. Assuming that energy sources are negligible, the energy equation can be written as

$$
\begin{aligned}
& \frac{\partial}{\partial x}\left(\rho v_{x} C_{p} T_{0}\right)+\frac{1}{r} \frac{\partial}{\partial r}\left(r \rho v_{r} C_{p} T_{0}\right) \\
&=\frac{\partial}{\partial x}\left(\lambda \frac{\partial T_{0}}{\partial x}\right)+\frac{1}{r} \frac{\partial}{\partial r}\left(r \lambda \frac{\partial T_{0}}{\partial r}\right)+W_{V}+E^{K}+\phi
\end{aligned}
$$

where $T_{0}$ is the total temperature:

$$
T_{0}=T+\frac{v^{2}}{2 C_{p}}
$$

$W_{V}$ is the volume change work:

$$
W_{V}=v_{j} \mu\left(\frac{\partial}{\partial x_{i}} \frac{\partial v_{j}}{\partial x_{i}}+\frac{\partial}{\partial x_{k}} \frac{\partial v_{k}}{\partial x_{j}}\right)
$$

$\phi$ is the dissipation energy:

$$
\phi=\mu\left(\frac{\partial v_{i}}{\partial x_{k}}+\frac{\partial v_{k}}{\partial x_{i}}\right) \frac{\partial v_{i}}{\partial x_{k}}
$$


and $E^{K}$ is the kinetic energy:

$$
E^{K}=-\frac{\partial}{\partial x}\left[\frac{\lambda}{C_{p}} \frac{\partial}{\partial x}\left(\frac{1}{2}\left|v^{2}\right|\right)\right]-\frac{\partial}{\partial r}\left[\frac{\lambda}{C_{p}} \frac{\partial}{\partial r}\left(\frac{1}{2}\left|v^{2}\right|\right)\right] .
$$

With cryogenic hydrogen as a coolant, temperature dependent fluid properties have to be considered. In view of it, the Sutherland approach for viscosity and thermal conductivity was used:

$$
\begin{aligned}
& \mu=\mu_{n}\left(\frac{T}{T_{n, \mu}}\right)^{1.5} \frac{T_{n, \mu}+\zeta_{\mu}}{T+\zeta_{\mu}} ; \\
& \lambda=\lambda_{n}\left(\frac{T}{T_{n, \lambda}}\right)^{1.5} \frac{T_{n, \lambda}+\zeta_{\lambda}}{T+\zeta_{\lambda}}
\end{aligned}
$$

where $\zeta_{\mu}$ is the Sutherland coefficient for the viscosity.

The nonuniform behavior of the fiber reinforced material is taken into account in form of orientation dependent coefficients of heat conductivity, head loss, and permeability in the energy equation (1) and Forchheimer equations:

$$
\begin{aligned}
& \frac{\partial p}{\partial x}=-\left\{K_{x} \rho v_{x}|v|+C_{x} \mu v_{x}\right\} \\
& \frac{\partial p}{\partial r}=-\left\{K_{r} \rho v_{r}|v|+C_{r} \mu v_{r}\right\}
\end{aligned}
$$

where $K_{x}$ and $K_{r}$ are the pressure loss coefficients; $C_{x}$ and $C_{r}$ are the permeability coefficients in axial and radial directions; and $v_{x}$ and $v_{r}$ are the respective Darcy velocities. The parameters $K_{x}, K_{r}, C_{x}$, and $C_{r}$ which describe the distributed resistance are determined by means of least square fit analyses of experimental results, given for a series of pressure differences for a test sample (for example, in the axial flow direction).

The example of a comparison between the results of the experimental determination of these parameters and numerical modeling is shown in Fig. 3 with quite reasonable agreement between them. In radial directions, the agreement is also good; however, the actual losses are larger. This nonhomogeneity of material parameters depends on different parameters, i.e., initial fiber diameter, processing steps, or possible three-dimensional (3D) reinforcement.

A zoom of the mesh for the interesting part, the porous liner, and the vicinity along the porous surface inside the combustion chamber is given in Fig. 4 and a sample result of a temperature distribution in the thrust chamber predicted with permeability coefficients derived from the measurements presented in Fig. 3 is shown in Fig. 5. For simplicity reasons and for concentrating all computational effort on the areas of interest, such aspects as atomization, mixing, and combustion have been neglected: the temperature in the combustion chamber was 


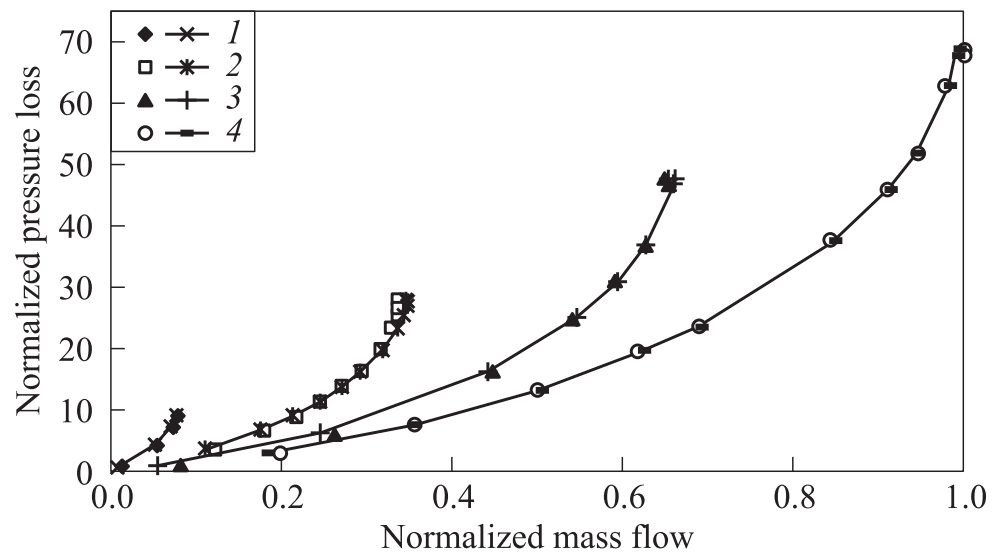

Figure 3 Comparison of experimental results (signs) and CFD results with fitted Forchheimer parameters (curves) for pressure loss in the axial flow direction in a cylindrical test sample: $1-10$ bar; $2-30 ; 3-50$; and $4-70$ bar

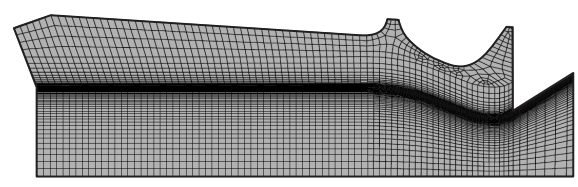

Figure 4 Meshing of the model in the area of the porous wall material

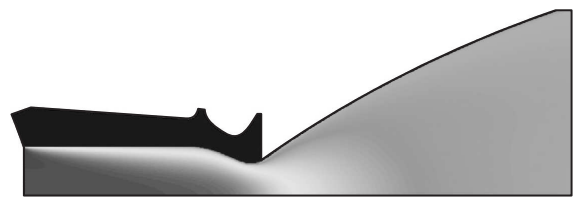

Figure 5 Temperature distribution along the liner wall

assumed to be equal to $3700 \mathrm{~K}$. The impact of the injected coolant along the porous liner is clearly visible. More recently, DLR started 3D simulation studies which include atomization and combustion as well, to allow more detailed studies of the interaction between injector flow and effusion boundary layer in the vicinity of the injector head.

\subsection{Propellant Injection and Atomization}

An essential function of the injector head assembly is to uniformly inject the propellants into the combustion chamber at the proper oxidizer-fuel mixture ratio, provide favorable conditions for jet disintegration and mixing, dampen secondary flows resulting from the turbopump or piping systems and at least partially decouple dynamically the propellant feed system from the combustion chamber. A major concern of any injector is the injector-wall interaction. In the vicinity of the face plate where propellant mixing is poor, oxidizer-rich gases 
mixed with cryogenic droplets may get in contact with the combustion chamber walls. The result of this process, a combined physical and chemical attack, yields visible traces of material degradation at the liner surface called 'blanching.' An entirely different approach compared to the high-precision-requirement coax or tricoax injectors is an approach with a porous face plate which is equipped with a large number of cheap, small tubes fabricated from standard hardware following a components-of-the-shelf (COTS) strategy to reduce cost. While the gaseous propellant is fed through the porous plate into the chamber, the liquid goes through these tubes. The advantage of this approach is that the dimen-

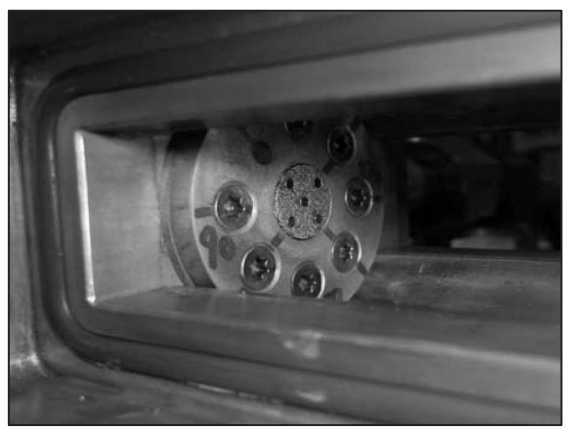

Figure 6 Porous penta-injector mounted in model combustor "C" sions of each element are so small that deviations from the required dimensions are tolerable since each element delivers something of the order of $0.1 \%$ of the total oxygen mass flow rate to the chamber and deviations affect only negligible parts of the combustion chamber volume. It is worth mentioning that the atomization process with this kind of injector is different compared to the one with conventional shear coax injectors. Distribution of the gaseous fuel all over the face plate considerably lowers the hydrogen velocity re-

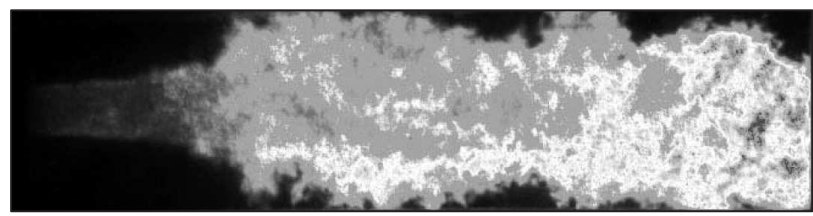

(a)

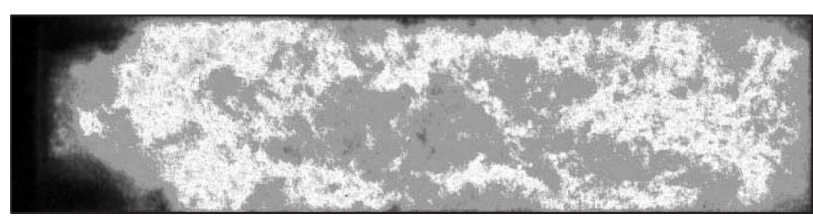

(b)

Figure 7 Comparison of the near face-plate region of a shear coax $(a)$ and porous $(b)$ injector 


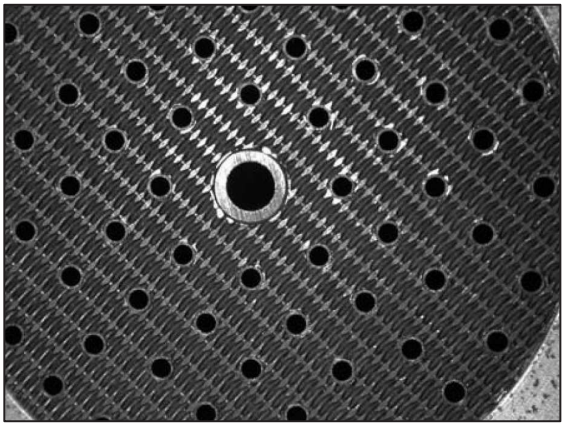

Figure 8 Subscale injector head for combustor "B" with Rigimesh ${ }^{\circledR}$ face plate

sulting, in turn, in reducing the aerodynamic forces available for atomization which seems to make this approach less attractive.

In order to study this type of injection system in more detail, DLR followed an approach aimed, first of all, at examining the near injector region. For this purpose, the DLR model combustor "C" was used which allows for optical access even at pressures exceeding $6 \mathrm{MPa}$. Test campaigns have been performed with single injector and multiinjector assemblies. As an example, Fig. 6 shows the multi (penta) injector arrangement mounted in the combustor. Compared to a typical shear coax injector, the combustion with a porous injector setup seems to take place much nearer to the face plate as shown in Fig. 7 which displays averaged $\mathrm{OH}$-emission pictures of a shear coax and porous injector at near-critical pressure conditions. Although atomization and combustion are shifted towards the injector, the cooling capability of the gaseous propellant seemed sufficient since no signs of intolerable high temperatures could be observed. Obviously, this change in heat release will have an impact on the heat load distribution along the liner compared to conventional shear coax injectors. Hence, in the second campaign, DLR applied its model combustor "B," a segmented multiinjector assembly with an inner diameter of $50 \mathrm{~mm}$ which is designed for combustion chamber pressures of $10 \mathrm{MPa}$, to study the head load distribution with a porous injection system. In order to verify the injector concept and to save time, this study was performed with an injection system fabricated using a Rigimesh ${ }^{\circledR}$ face plate (Fig. 8). The results confirmed the shift of the heat release towards the face plate observed with combustor "C." The differences in the local heat fluxes to the liner wall at a given downstream position may exceed $50 \%$.

\section{NOZZLE TECHNOLOGIES}

Over the past years, Astrium has, together with various partners, worked intensely on developing components for air-breathing and liquid rocket engines. Various prototype developments and hot firing-tests with nozzle extensions designed for upper and core stage engines and combustion chambers of satellite engines were conducted. MBDA France and Astrium have been working on 


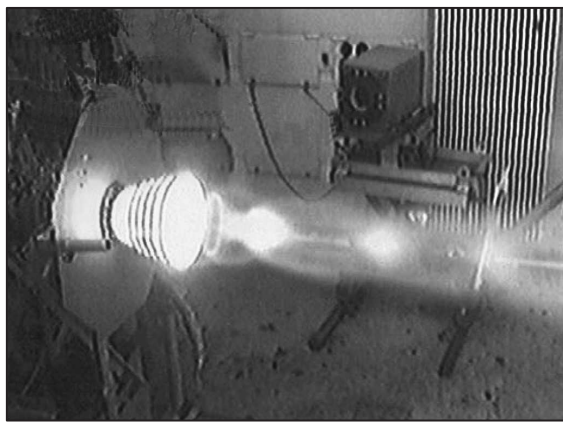

(a)

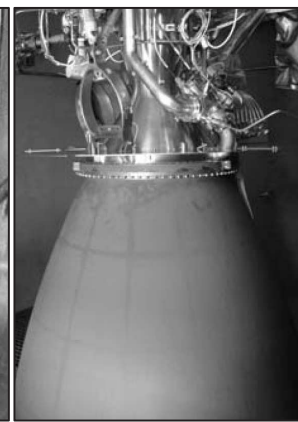

(b)

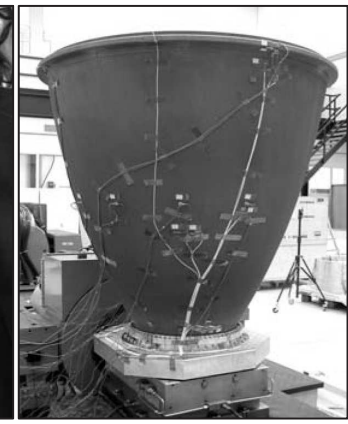

(c)

Figure 9 Hot test of nozzle extension (a); full-scale upper-stage nozzle extension on test facility $(b)$; and during vibration test $(c)$

the development of fuel-cooled composite structures like combustion chambers and nozzle extensions for future propulsion applications. In view of the extreme thermomechanical loads in the combustion chamber of liquid-propellant rocket engines, previous developments at Astrium were focussed above all on the use of ceramic fiber composites for the less thermally loaded nozzle extensions. At Astrium, nozzle extensions made of SICARBON ${ }^{\mathrm{R}}$ have been developed for upper-stage (scale 1:1) and main-stage (scale 1:5) engines and successfully tested under real space conditions. Further test campaigns with radiation-cooled combustion chambers were carried out in the field of satellite propulsion, whereby the SICARBON ${ }^{\circledR}$ material was able to demonstrate its long-term stability and high chemical compatibility vs. the propellants and combustion products in hot-firing tests carried out at sea level conditions [10] (Fig. 9).

The development of ceramic nozzle extensions for rocket engines represents an increasingly recognizable problem: In the current design, the ceramic nozzles are carried out in single-shell and passively cooled structures. The exclusively used cooling concept of currently existing ceramic nozzles of upper-stage engines (VINCI, RL10-B2) is, based on the today's knowledge level, however, insufficient to guaranty the thermomechanical integrity of future high-performance rocketengine structures. Due to the elevated thermal loads experienced by a main-stage engine nozzle, a design without active cooling is not conceivable.

Based on the experiences with the development of fuel-cooled ceramic combustion chambers for air-breathing engines for Dual-Mode Ramjets (DMR's) [5, $8,10,12]$, preliminary investigations have been performed to outline the possibilities and interest of using the PTAH-SOCAR (Paroi Tissée Application Hypersonique-Simple Operational Composite for Advanced Ramjet) technology for actively cooled nozzles of LREs. System studies undertaken at Astrium as well as structural and thermal analyses promise, thanks to the use of CMCs in 


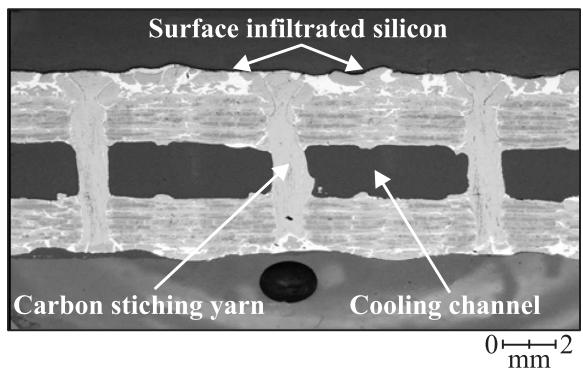

(a)

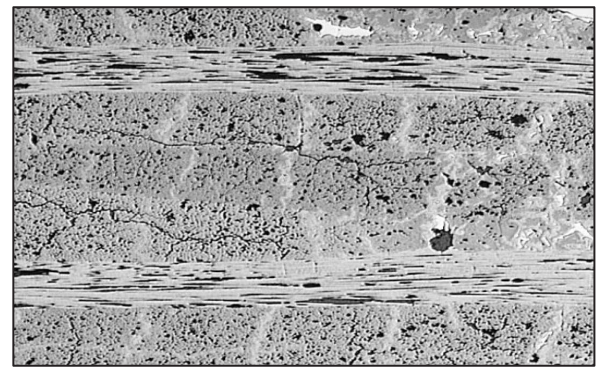

(b)

Figure 10 Sandwich structure with cooling channels $(a)$ and cross section of SICTEX $^{\circledR}$ SI material $(b)$

the thrust chambers of LREs, substantial advantages compared to metal materials, which are currently utilized in most launcher propulsion systems for cooled combustion-chamber structures and nozzle extensions. The main advantages comprise, on the one hand, the possible weight reduction and, on the other hand, the high resistance to thermoshocks as well as the resistance to chemical attack vs. the liquid propellants used. A further significant advantage is the high creep resistance and the extraordinary resistance to high temperatures compared to metal materials.

However, the multiaxial states of stress occurring especially in actively cooled thrust chambers and nozzles necessitate a fiber composite that features sufficient shear strength in as many directions as possible (e.g., isotropic behavior). The currently available 2-directional fiber composites would probably only have very limited lifetimes with respect to damage tolerance. For this reason, some years ago, the development of a new material system and manufacturing process, respectively, was commenced, with the objective of combining multidirectional (3D) textile structures with a cost-effective infiltration method. A cross section of the SICTEX ${ }^{\mathrm{R}}(\mathrm{C} / \mathrm{C}-\mathrm{SiC}$ surface infiltrated) Fuel-Cooled Combustion Chamber (FCCC) is shown in Fig. 10.

The potential interests of using CMC's for rocket nozzles are an increased component lifetime since thermal cyclic sensitivity is negligible compared to current metallic structures, light weight design capability, increased cooling concept flexibility (regenerative, dump, film, effusion), and performance gain due to less weight and reduced cooling requirements. Astrium's part within the 'Propulsion 2010' project bases on the PTAH-SOCAR design and composite material technology. Figure 11 shows a sketch of the fuel-cooled CMC subscale nozzle design. The geometry and contour of the nozzle is based on a VULCAIN nozzle downscale and is modified into a dual-bell shape. While the fuel-cooled section extends to an area ratio of $\varepsilon=32$, an exchangeable ceramic skirt up to an area ratio of $\varepsilon=60$ secures the performance target. The nozzle layout was driven 


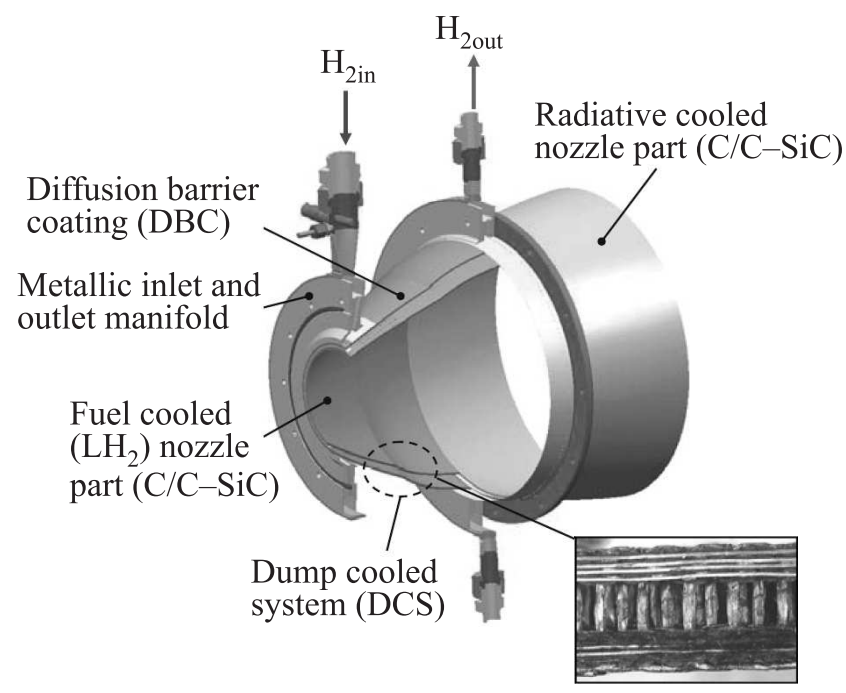

Figure 11 Fuel-cooled CMC dual-bell nozzle

by envisaged $\mathrm{LOX} / \mathrm{H}_{2}$ hot firing tests operated at the P8 test facility in Lampoldshausen with a chamber pressure of $p_{c}=100$ bar and a mixture ratio of $\mathrm{O} / \mathrm{F}=6$. The interface to the combustion chamber at an area ratio of $\varepsilon=5$ has been designed to be compatible to an existing Astrium 4000-newton subscale thruster. This gave the opportunity to test the nozzle device even prior to the ceramic motor test campaign as a passenger. To approach as best as possible the conditions of potential full-scale applications, hydrogen has been selected as a coolant. Moreover, the specified hydrogen inlet pressure of 80 bar is fully representative for a dump cooled nozzle system as currently used in the VULCAIN 2 engine.

From a thermal layout point of view, two challenges had to be mastered. Firstly, the heat flux distribution along a hot wall in a supersonic flow had to be determined very precisely and secondly, the coolant efficiency in a pin fin structure with rough ceramic surfaces had to be evaluated. For the latter, an advanced Nusselt-type correlation including surface roughness effects has been applied. Additional pressure drop and heat transfer enhancement induced by the pin fins have been estimated. The heat flux profile imposed by the hot gas flow has been assessed using computational fluid dynamics (CFD) with detailed chemistry modeling. Prior to its application, the methodology had been anchored to the aforementioned SICARBON ${ }^{\circledR}$. nozzle tests. In particular, the predicted gas composition close to the hot ceramic wall was found to crucially determine the transport properties and hence the heat fluxes. Figure $12 a$ displays the simulated Mach number distribution within the dual-bell nozzle and Fig. $12 b$ displays two 


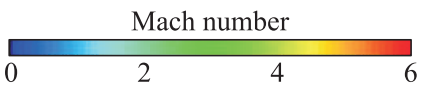

Contour deflection point

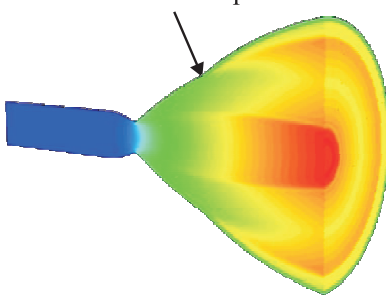

(a)

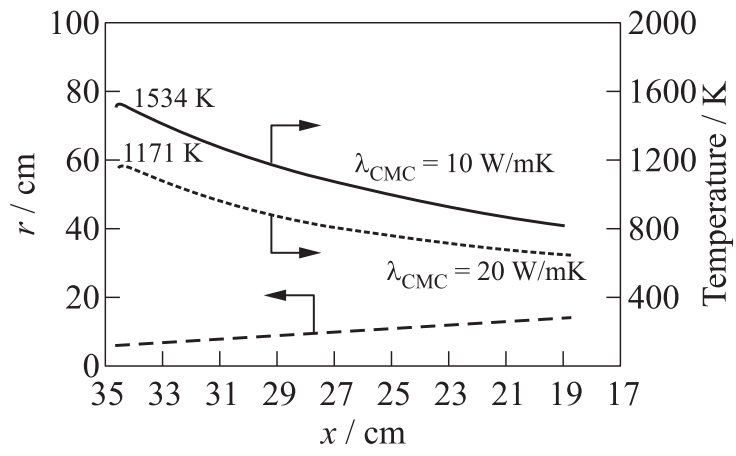

(b)

Figure 12 The thermal layout of the subscale FCCN conducted with Astrium's advanced heat transfer tools [16]: $p_{c}=100 \mathrm{bar}, \mathrm{O} / \mathrm{F}=6$, and $T_{\mathrm{H}_{2 \text { in }}}=293 \mathrm{~K}$. (Refer Haidn et al., p. 656.)
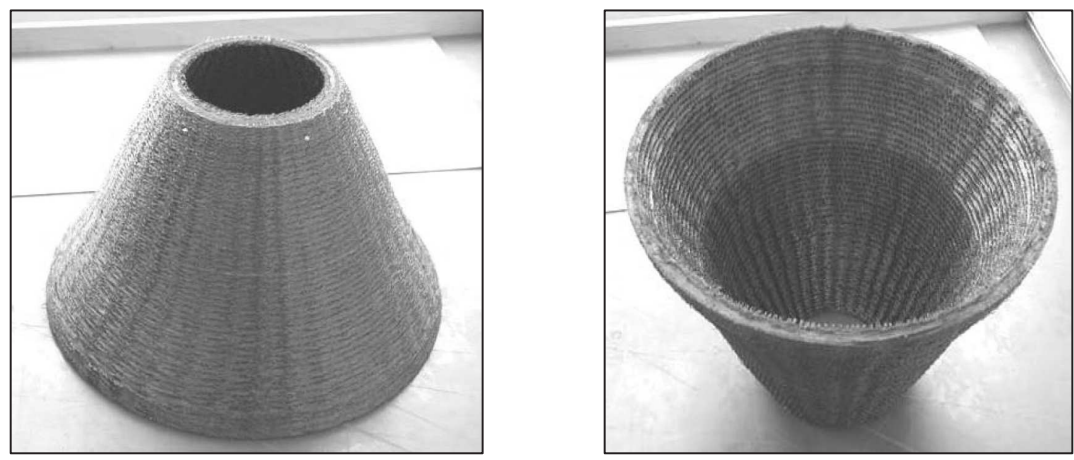

Figure 13 Braided and densified dual-bell nozzle extension prototype

typical wall temperature profiles along the regenerative cooled nozzle part $(x=0$ corresponds to nozzle exit) depending on the realized radial thermal conductivity of the CMC material at a given coolant flow rate. Apparently, the latter coolant flow rate can further be reduced to reach the temperature limit of the ceramics.

In the first approach, the design work and the prototype manufacturing of a Fuel-Cooled-Ceramic-Nozzle (FCCN) Extension has taken place. The investigation of heat transfer and pressure drop of the sandwich structure has shown that the effect on wall temperatures because of a reduction of the channel height is not significant but in opposite, there is a severe influence on the pressure loss. Further on, an essential reduction of the coolant mass flow rate is possible and there is no critical heat conductivity influence of pin fins on the wall temper- 
atures to be expected. A first nozzle prototype has been produced by textile technique and Fig. 13 shows the braided and densified prototype.

\section{CONCLUDING REMARKS}

The development of an actively cooled nozzle structure represents a special challenge to CMC structure regarding thermal conductivity, damage tolerance, tightness, and joining technique. Besides the development of the joining of the metallic manifolds with the ceramic structure, the setting of a defined porosity on hot gas wall side to influence the permeability is solved and in certain limits, reproducible. Using liquid hydrogen as a coolant, absolute tightness has to be achieved to fulfil the system requirement, and special coating systems are under development to seal the outer shell of the nozzle.

Besides the material-related problems mentioned above, the major technical challenges for the development of the propellant injection system and the combustion chamber liner are the compatibility of the spray pattern with the requirements of the liner in the vicinity of the injector, the cryogenic temperatures of both propellants for gas generator engine cycle applications, and the local adaptation of the coolant requirements to the varying thermal loads. The technical challenges must be solved and verified in the coming years to test the ceramic nozzle and the ceramic combustion chamber on the test bench in 2010 .

\section{SUMMARY AND OUTLOOK}

Within the 'Propulsion 2010' MoU, Astrium and DLR have agreed to cooperate in the field of development of CMC components for the application of LREs by combining their competences and resources with the aim to develop a subscale thruster based on CMC components. Although key technologies have already been developed and verified during the last years, there are still technical challenges which remain to be mastered. However, in the upcoming years, Astrium and DLR will continue their cooperation and work closely together to reach the goal and have a thrust chamber assembly made of CMC materials ready for a test campaign at the European R\&D facility P8 at DLR Lampoldshausen.

\section{REFERENCES}

1. Lezuo, Michael K. 1998. Heat transfer in $\mathrm{H}_{2}$ transpiration cooled thrust chamber components. Ph.D. Thesis. RWTH Aachen. (In German.)

2. Beyer, S., H. Knabe, and F. Strobel. 1999. Development and testing of C/SiC components for liquid rocket propulsion applications. AIAA Paper No. 99-2896. 
3. Serbest, E., O. J. Haidn, H. Hald, G. Korger, and P. Winkelmann. 1999. Effusion cooling in rocket combustors applying fiber reinforced ceramics. AIAA Paper No. 99-2911.

4. Serbest, E., O. J. Haidn, H. Hald, G. Korger, P. Winkelmann, and K. Fritscher. 1999. Advanced technologies and materials for future liquid rocket engines. 12th European Aerospace Conference. Paris.

5. Krenkel, W. 2000. Development of a low-cost production process for ceramic matrix composite structures. Ph.D. Thesis. Stuttgart.

6. Meinert, J., J. Huhn, E. Serbest, and O. J. Haidn. 2001. Turbulent boundary layers with foreign gas transpiration. J. Spacecraft Rockets 38(2):191-98.

7. Serbest, E. 2001. Investigation of the application of effusion cooling in thrust chambers. Ph.D. Thesis. RWTH Aachen. (In German.)

8. Kindermann, R., S. Beyer, T. Sebald, C. Hollmann, B. Denkena, T. Friemuth, M. Kaufeld, and U. Kolb. 2002. Advanced production and process technologies for current and future thrust chambers of liquid rocket engines. 4th Conference (International) on Launcher Technology. Liege.

9. Schmidt, S., S. Beyer, H. Knabe, H. Immich, R. Meistring, and A. Gessler. 2003. Advanced ceramic matrix composite materials for current and future propulsion technology applications. 54th Astronautical Congress (International) Proceedings. IAC-03-S.3.03.

10. Schmidt, S., S. Beyer, G. Cahuzac, R. Meistring, H. Knabe, and M. Bouchez. 2004. Advanced ceramic matrix composite materials for current and future propulsion technology applications. 5th Conference (International) on High-Temperature Ceramic Matrix Composites. Seattle.

11. Bouchez, M., S. Beyer, and G. Cahuzac. 2004. PTAH-SOCAR fuel-cooled composite materials structure for dual-mode ramjet and liquid rocket engines. AIAA Paper No. 2004-3653.

12. Beyer, S., S. Schmidt, F. Maidl, R. Meistring, M. Bouchez, and P. Peres. 2006. Advanced composite materials for current and future propulsion and industrial applications. 11th Ceramics Congress (International) and 4th Forum on New Materials. Acireale, Italy.

13. Greuel, D., A. Herbertz, O. J. Haidn, M. Ortelt, and H. Hald. 2004. Transpiration cooling applied to C/C liners of cryogenic liquid rocket engines. Symposium (International) on Space Propulsion Proceedings. Shanghai. 38-62.

14. Haidn, O. J., D. Greuel, A. Herbertz, M. Ortelt, and H. Hald. 2005. Application of fiber reinforced $\mathrm{C} / \mathrm{C}$ ceramic structures in liquid rocket engines. In: Rocket motors and problems of space exploration. Vol. 1. Space challenge in XXI century ser. Eds. I. G. Assovskiy and O. J. Haidn. Moscow: TORUS PRESS. 78-104.

15. Suslov, D., J. Lux, and O. J. Haidn. 2007. Investigation of porous injector elements for $\mathrm{LOX} / \mathrm{CH}_{4}$ and $\mathrm{LOX} / \mathrm{H}_{2}$ combustion at sub- and supercritical conditions. 2nd Conference (European) for Aerospace Sciences (EUCASS). Brussels.

16. Knab, O., A. Fröhlich, J. Görgen, and D. Wiedmann. 2002. Advanced thrust chamber layout tools. 4th Conference (International) on Launcher Technology "Space Launcher Liquid Propulsion" Proceedings. Liege, Belgium. 